\title{
Is It Time to Rethink the Way We Assess the Burden of Work-Related Cancer?
}

\author{
Emilie Counil ${ }^{1,2} \cdot$ Emmanuel Henry $^{3}$
}

Published online: 26 April 2019

(C) The Author(s) 2019

\begin{abstract}
Purpose of Review Population attributable fractions (PAFs) are increasingly used for setting cancer prevention priorities. Our review aims, first, to gather published estimates of the percentage of cancer attributed to causal agents in the workplace and, second, to analyze them from the perspective of their potential effects on population health inequities.

Recent Findings The estimates generally ranged from less than $2 \%$ to more than $8 \%$, with an average of $4-5 \%$. While most authors acknowledge that exposures concentrate in lower-socioeconomic status and more vulnerable workers, the literature has never considered the occupational group as a source of variation in the calculations. This knowledge gap is linked to the paucity of data describing the occupational patterning of exposures and cancer. More globally, the social gradient in cancer is often interpreted in the light of behavioral factors alone, a tendency linked by historians to the very foundations of modern epidemiology. Yet, there is accumulated evidence that work affects health and the risk of death through different pathways, which are also relevant to cancer.

Summary While the epidemiologic literature addressed conceptual and validity issues surrounding PAFs, it seldom questioned their potential impacts. There is in particular a lack of consideration of factors beyond individual behaviors and a paucity of attention to population health inequities. We hence propose to further the discipline's reflexivity by changing the focus, scope, and metrics in order to assess the burden of work-related cancer in a way that is more meaningful to the most disadvantaged workers.
\end{abstract}

Keywords Attributable fraction $\cdot$ Carcinoma $\cdot$ Occupational exposures $\cdot$ Health inequities $\cdot$ Undone science

\section{Introduction}

The concept of attributable fraction was promoted by epidemiologists in the early 1950 s to quantify the proportion of people afflicted by lung cancer whose disease was attributable to cigarette smoking $[1,2]$. It was further used as a surrogate to

This article is part of the Topical Collection on Cancer Epidemiology

Emilie Counil

emilie.counil@ined.fr

1 Institut national d'etudes démographiques (INED), F-75020 Paris, France

2 IRIS, EHESS, CNRS (UMR 8156), INSERM(U997), Université Paris 13, F-93017 Bobigny, France

3 IRISSO, INRA, CNRS, Université Paris-Dauphine, PSL University, F-75016 Paris, France estimate potential health gains through reduction of exposures to causal agents, specifically by interpreting it as the proportion of adverse outcome that could be averted if the exposure were either eliminated or reduced to a minimum-risk level. Calculating a population attributable fraction (PAF) typically requires the combination of two dimensions that influence occurrences of new "cases" in populations: relative risk (RR) and prevalence of exposure. Since the Levin formula, multiple mathematical constructs have been proposed for this purpose $[3 \bullet \bullet, 4 \bullet \cdot, 5 \bullet \cdot]$. The attributable fraction also plays an important role in public debates on public health issues and has become one of the tools used to promote evidence-based policy-making $[6 \cdot \bullet]$. It is considered a critical driver of cancer prevention in general [7] and occupational cancer in particular [8]. In a still highly cited report by Doll and Peto, released in 1981 [9], the PAF for occupational exposures amounted to 4\% of total US cancer deaths in 1978 among people aged 65 or less (uncertainty range 2-8\%). Of particular interest is that those early estimates have been globally replicated over the 
past four decades [10] while trends in exposures have changed, different methods have been developed and new sources of data have emerged.

The aim of the present review is to gather recent estimates of total occupational cancer burden, to analyze whether and how they differ from the landmark figures and to describe how a focus on individual risk factors like smoking may have translated in an undercounting of cancers attributed to occupational exposures. Specifically, this article calls to attention the extent to which this tool has contributed to specifically defining occupational cancers, by focusing attention on some aspects such as their lesser importance compared with tobacco and diet issues, while ignoring or minimizing others such as their concentration among smaller groups (geographically or socially defined) that are very significantly affected. Finally, potential areas of improvement are identified in order to hopefully help us rethink how we assess the burden of work-related cancer.

\section{Doll and Peto's Landmark Estimates: Do They Generally Hold True?}

The latest review finds that the occupational PAF estimates published since Doll and Peto's report generally ranged from 2 to $8 \%$ in the USA, Great Britain, and Nordic countries [11 • ]. In that respect, the British figures published in 2012 by Lesley Rushton and her team may well constitute the landmark estimates of their day, with point estimates of $5.3 \%$ for cancer deaths and $4.0 \%$ for incident cancer [12]. PAFs were systematically higher among men (3 to 14\%) than among women (1 to $2 \%$ ). The major contributors to the burden of deaths were lung cancer, mesothelioma, and bladder cancer [13], with other tumors also being important for men (such as the larynx, nasal cavity, and kidney). Additional sites proved significant in terms of incidence, namely nonmelanoma skin cancer for both men and women, and breast cancer in women when shift work was considered [12].

In Table 1, we further the review of PAFs published since 2012 among populations of high income countries (HIC). The latest estimates focus increasingly on incidence and usually amount to 2 to $4 \%$, except in Québec, where they reached 6\% in the mid-2000s according to PAFs borrowed from Finland and Great Britain [18•]. Since those original UK estimates [12], only France has based its calculations on detailed national exposure data or the best available proxy [14*0]. Indeed, the British update of $3.8 \%$ [15] is based on previous estimates [19], while the supposedly updated figures for the USA appear in a table with no reference to data sources or methods [17].

Looking back to the figures that have circulated in scientific reports and peer-reviewed publications since the unusually high figures proposed in the 1978 OSHA report [20] (which were quickly dismissed by the $4 \%$ report), we may group these estimates into three levels. The first group comprises very low figures of around or below $2 \%$, which rather relate to incidence (2.3\% in France [14.•]; $2 \%$ in Nordic countries [21]), and women in general (from $0.4 \%$ [14.•] to $2.7 \%$ $[18 \bullet])$. The second group comprises intermediate estimates of around 4-5\% (incidence or mortality), which are in line with Doll and Peto's contribution [12, 15, 17]). The third group reports relatively higher estimates of around 8 to $10 \%$ and refers exclusively to deaths (7.6\% in Québec [18•], 8.6\% in Australia [16 $\left.\left.{ }^{\circ}\right]\right)$ and to men (8.2\% in Great Britain [12], $13.8 \%$ in Finland [22]).

\section{Sources of Variation: Occupational Class Missing}

The above are examples of the influence of country, period, outcome, and sex. However, with respect to the gender gap, it remains uncertain the extent to which these PAFs actually reflect differences due to segregation of jobs and exposures or if they are grounded in gender bias resulting in a potential underestimation among women. There is actually a range of sex-related methodological biases (from the lesser inclusion of women in occupational health studies, to double standard issues in the assessment of their exposures) that may result in an underestimation of occupational risk factors [23-25]. Another important source of variation is the number of agent-tumor combinations that are included. This, in turn, depends on the available level of evidence, and the more or less conservative approaches used to assess causality. For example, the recent estimates for France ranged from 2.3\% (3.9\% in men, 0.4\% in women) when considering Group 1 carcinogens alone (e.g., defined as "carcinogenic to humans" by the International Agency for Research on Cancer, Iarc) to $3.5 \%$ (5.7\% in men, $1.0 \%$ in women) when further adding Iarc Group 2A carcinogens (e.g., those "probably carcinogenic to humans," meaning less conclusive epidemiological evidence). The actual inclusion of a given combination will then rely on the availability of relevant input data, which may often be lacking. The results are also highly influenced by the choice of RR, the metric used to define prevalence of exposure (latency, categories) and their concordance [4••]. As an illustration, Fig. 1 simulates variations in PAFs based on the respective values chosen for RR and prevalence of exposure.

Both components are also likely to vary by industry sector, as shown in the UK, where $2.0 \%$ of the attributed cancers were in agriculture, forestry, and fishing; $29.9 \%$ in manufacturing and mining; $41.0 \%$ in construction; and, interestingly, $30.2 \%$ in the service industries [26]. Although barely addressed, other sources of variability include outcome (premature mortality), age range, and geographic (subnational) area. Though data are scant, a French report estimated that 
Table 1 Recent PAF estimates of cancer related to occupational exposures in high income countries

\begin{tabular}{|c|c|c|c|c|c|c|c|c|c|}
\hline \multirow[t]{2}{*}{ Reference } & \multirow[t]{2}{*}{ Country } & \multirow[t]{2}{*}{ Outcome } & \multirow[t]{2}{*}{ Year } & \multicolumn{2}{|l|}{ All } & \multicolumn{2}{|l|}{ Men } & \multicolumn{2}{|l|}{ Women } \\
\hline & & & & PAF (\%) & Range $^{1}$ & PAF (\%) & Range & PAF $(\%)$ & Range \\
\hline \multirow[t]{2}{*}{ [14] } & \multirow[t]{2}{*}{ France } & Incidence & 2015 & 2.3 & & 3.9 & & 0.4 & \\
\hline & & Incidence $^{2}$ & 2015 & 3.5 & & 5.7 & & 1.0 & \\
\hline$[15]$ & UK & Incidence & 2015 & 3.8 & & 5.0 & & 2.5 & \\
\hline [16] & Australia $^{3}$ & Mortality & 2015 & 8.6 & $(7.4-9.6)$ & 13.1 & $(11.3-15.0)$ & 2.4 & $(2.0-3.0)$ \\
\hline [17] & USA & Mortality & 2000-2010 & & & 4.0 & $(3.0-5.0)$ & $\leq 1$ & \\
\hline \multirow[t]{2}{*}{ [18] } & \multirow[t]{2}{*}{ Québec ${ }^{4}$} & Mortality & $2002-2006$ & 7.6 & $(6.9-10.9)$ & 11.7 & $(11.0-17.3)$ & 2.8 & $(2.1-3.6)$ \\
\hline & & Incidence & 2002-2006 & 6.0 & $(5.0-8.4)$ & 9.1 & $(8.3-13.2)$ & 2.7 & $(1.6-3.3)$ \\
\hline \multirow[t]{2}{*}{ [12] } & \multirow[t]{2}{*}{ UK } & Mortality & 2005 & 5.3 & $(4.6-6.6)$ & 8.2 & $(7.2-9.9)$ & 2.3 & $(1.7-3.2)$ \\
\hline & & Incidence & 2004 & 4.0 & $(2.7-5.9)$ & 5.7 & $(4.0-8.4)$ & 2.1 & $(1.4-3.2)$ \\
\hline
\end{tabular}

${ }^{1}$ Range, when provided by authors, usually refers to the uncertainty interval as estimated through either sensitivity analysis or comparison of low, plausible (or medium), and high scenarios, except in (12), where range represents $95 \%$ confidence intervals

${ }^{2}$ These estimates are based on a secondary analysis relaxing the causal criteria for a range of agent-tumor combinations (e.g., Iarc Group 1 and $2 \mathrm{~A}$ carcinogens)

${ }^{3}$ These estimates were based on the Global Burden of Disease (GBD) 2015 study, which uses a distinct methodology

${ }^{4}$ These estimates are based on the selection of "plausible" attributable fractions published for different cancer sites, their translation into attributable cases in Québec, and further summing to derive an overall PAF for all cancer

PAFs for lung cancer and asbestos among men ranged from $5 \%$ in the $30-34$-year age group to $16 \%$ in those aged 40 years and more, a gap explained by differences in lifetime prevalence of exposure [27]. In Italy, a review showed large variations in the fraction of lung cancer attributed to occupation depending on period and geographical prevalence of hazardous industries [28]; while a population-based case-control study conducted in a former highly industrialized area reported AF for lung cancer higher than $50 \%$ in French men aged 40-79 [29]. These observations indirectly mirror what most authors acknowledge when it comes to interpreting occupational PAFs, namely that "occupational cancer tends to be concentrated among relatively small groups of people among whom the risk of developing the disease may be quite large" [9]. Put in other words "if one considered the segments of the adult population in which exposures to occupational carcinogens almost exclusively occur (manual workers in mining, agriculture, and industry, broadly taken), the proportion of $4 \%$ in the overall population would increase substantially" [30]. When looking for estimates of attributable fractions among highly exposed (and sometimes to multiple hazards) sub-groups in the general population or even stratified
Fig. 1 Sensitivity analysis of Attributable Fraction (AF) estimates ( $Y$ axis) based on theoretical combinations of relative risk (RR, $X$ axis) and prevalence of exposure $(\operatorname{Pr}(\mathrm{E})$, series)

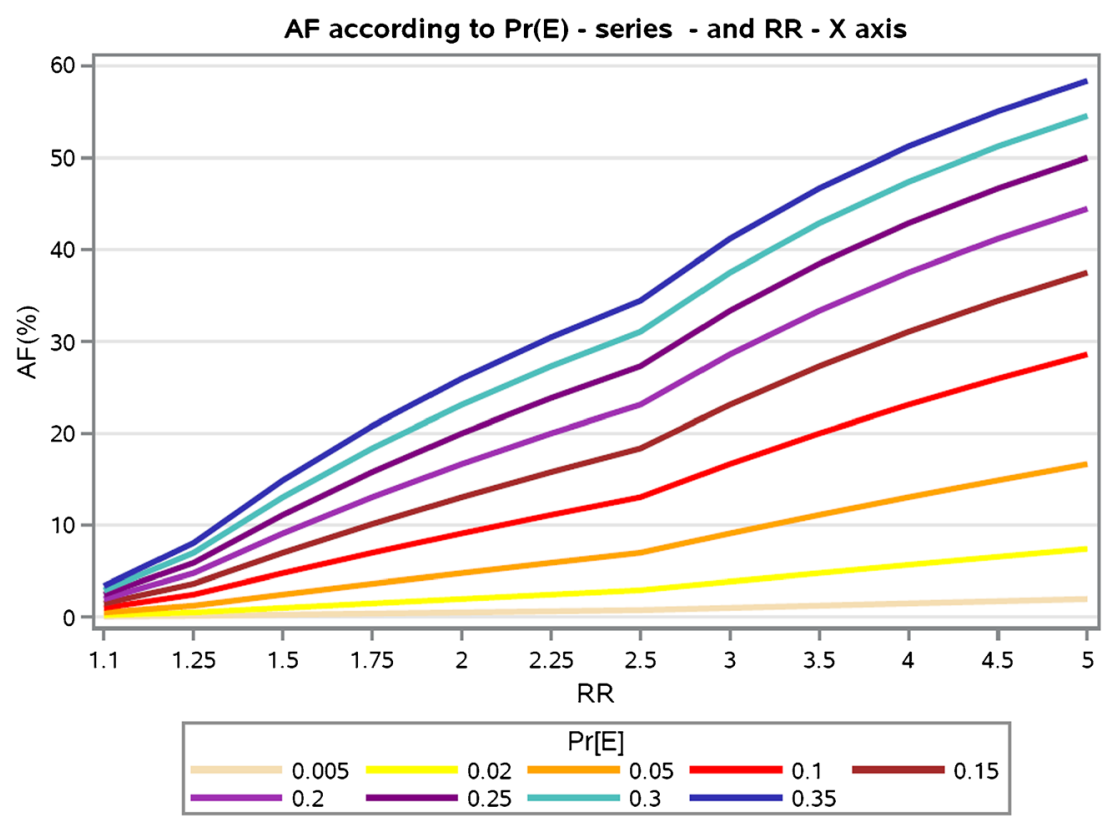


by broad occupational categories (managers, manual workers), we were still unable to find any paper published to date.

\section{A Case of Undone Science That Affects Lower-Status Workers}

Recent trends in science studies have emphasized that knowledge does not develop uniformly but that various social factors explain the production of both knowledge and ignorance [31]. More specifically, some studies have highlighted the structural inequalities that can lead to the significant development of certain fields of knowledge and, on the contrary, to a lack of interest in other issues referring to it as "undone science" [32••]. From this perspective, this lack of interest in lower-status workers seems to us to fall into this category. This echoes concerns that were already expressed long ago by different authors [33-37] and reiterated recently [38・•], though not specifically about PAFs and the occupational gradient of cancer.

This knowledge gap starts with the irregular and incomplete description of occupational exposures to carcinogens, and it is made even wider by the few data documenting their social patterning. Workplace exposure databases usually rely on monitoring systems of uncertain coverage and sustainability $[39,40]$. Large initiatives such as the European CARcinogen EXposure database (CAREX) [41] and CAREX Canada [42] have provided nationwide estimates for the current number of workers exposed in different occupational groups. Other countries have instead conducted either one-time (Australia [43]) or repeated cross-sectional studies (France [44•]) to monitor the prevalence of hazardous exposures at work. The French SUMER surveys (SUrveillance Médicale des Expositions aux Risques professionnels) are among the few that allow quantifying exposure variations by occupational group (up to $28.5 \%$ exposed to CMRs in skilled $\mathrm{BCW}$ ); function (up to $36.7 \%$ in installation, repair, and maintenance); and sex [44•]. Different trends are also observed for apprentices (e.g., increasing from 22.5 to $27.2 \%$ between 2003 and 2010) [45] and a lower level of control is observed in unskilled workers [46]. We nevertheless lack the global data on lifelong prevalence that is required in forming a clearer picture of the social stratification of work exposures in the general population over the life course. This is even more the case among the most disempowered workers (unskilled, temporary, non-unionized workers) that are most highly represented by women, people of color, and their intersection [47-49]. Moreover, occupational health studies (even more so labor statistics) typically do not include those who work in the informal sectors, "including very dangerous trades such as sex work, drug trafficking, personal and domestic services, nor the very dangerous exposures incurred during military service" [37]. The latter observations exemplify the "socially patterned gaps in knowledge about worker's health" [36]. Another gap in our knowledge concerns the common reliance on education rather than occupational group to capture the social gradient in cancer. Several HIC lack even the possibility of producing regular estimates of cause-specific death rates by occupation, as in France [50]; or they base their analyses on broad occupational categories, as observed in Belgium [51], Italy [52], and a recent 14-European country initiative focusing on middle-aged men [53*0]. The problem is even greater for incidence data, although with certain notable exceptions such as the Nordic countries [54].

\section{On the Relative Importance of Work and Way of Life}

Interestingly, in the face of the accumulated evidence that socioeconomic disparities in health are still rising, notably in Europe [55], the interpretation of the gradient continues to question the relative importance of (social) causation and (health) selection (the healthy worker effect). Even when causation is thought to outweigh selection, as suggested recently in the transition from working to old age [56], the question raised by early studies on occupational health disparities remains: How much does the mortality (morbidity) of an occupational group reflect work environment and how much can be ascribed to way of life [57]? This echoes Alice Hamilton's early thoughts about the passionate debates opposing innate and socially constructed disparities in worker's health based on gender and race/ethnicity (Hamilton, 1925, cited by [36]). For cancer in particular, some authors have suggested that as much as $30 \%$ of the social disparities in mortality could be attributed to occupational exposures [58], while others instead conclude that "although cancer risk varies by occupation, only a smaller part of the variation can be attributed to occupational exposures in the strict sense." [59]. Many social and some occupational epidemiologists do argue that physical and chemical hazards in the workplace contribute minimally to the socioeconomic gradients in health and mortality, although Clougherty and her colleagues propose three presuppositions that may have contributed to this argument [37]. Firstly, those gradients were demonstrated among cohorts of white-collar workers, implying that such exposures are not a necessary component. Secondly, work-related physical and chemical hazards are said to have drastically declined in HIC over recent decades. Thirdly, the belief has long been held that most workers enrolled in hazardous occupations are compensated for the extra-risk through higher wages, which might mitigate the adverse health effects of hazardous exposures. Arguing against these three premises, the authors conclude that - at least for respiratory diseases and cancer-physical and chemical hazards in the work environment most likely play an 
important role in the higher rates of disease among lowerstatus workers. This public health and social justice issue has too often been overlooked when discussing priorities in cancer prevention.

\section{Can We Take Late Lessons from Early Warnings?}

If we simultaneously pay heed to the social stratification of occupational exposures, health and mortality, as well as to the socially patterned knowledge gaps in how such inequalities impact the population, then we cannot help but conclude that the time has come to rethink the way we assess the burden of work-related cancers. Yet, above all, it seems that the most necessary step to take is becoming more reflexive in regard to our own practices, not only in terms of scientific validity but also in terms of social liability.

\section{Examining PAFs Through Science Studies}

Indeed, as public policies are increasingly shaped by epidemiology, it is important not only to improve its tools scientifically but also to question them from a sociological and historical perspective. The development of PAFs may then be viewed as emblematic of the prominence of risk factor epidemiology over the last 30-40 years [60], an influence that has been achieved at the expense of other approaches that previously prevailed and that were more clinically grounded. This includes the epidemiology of occupational cancer developed by Wilhelm Hueper before World War II [61, 62]. By relying on much larger groups from a variety of socio-professional backgrounds, "modern epidemiology" [63] has sharpened its focus on some major public health risks threatening large populations, with the most representative of them being tobaccorelated lung cancers [64]. However, the development of these approaches also made it more difficult to understand less massive risks and particularly when people experience multiple exposures. This issue is highly critical for occupational hazards, as work-related cancers tend to concentrate among small groups who potentially experience high disease risks; thus, providing an opportunity for reduction or even elimination. In the words of Doll and Peto: "The detection of occupational hazards should therefore have a higher priority in any programme of cancer prevention than their proportional importance might suggest" [9].

This latter point is illustrative of another dimension in the scientific works that compute PAFs. Situated at the boundary between the need to deepen knowledge and the willingness to guide public health interventions, such works are actually embedded in prevention policies $[65,66]$, which implies that researchers make choices regarding causes for which they think intervention is possible. Even categories such as "environmental" and "occupational" have not been consolidated within the field of epidemiology and they are subject to conflicting statements [67-70]. Today, the debates visibly shift from discussing "avoidable" to "preventable" burden of disease as concern grows about connecting PAFs to potential interventions through the quantification of an "attainable" risk reduction, e.g., through population preventable fractions (PPFs) [4••, 71]. Of course, defining what is and is not "attainable" is anything but scientific, nor is the selection of "modifiable" causes of cancers. Instead, such definitions and selections serve as very good examples of the type of socioeconomic expertise that decision-makers increasingly use when seeking to promote evidence-based public policies $[72,73]$.

Coming back to the history of quantifying work-related cancers, the consequences of Doll and Peto's report in the social and political arenas were even more important than its scientific impact. This report was actually commissioned by the US Congress's Office of Technology Assessment (OTA) in order to end the controversy surrounding the evaluation of occupational and environmental causes of cancers. This controversy had been stirred by the publication of The Politics of Cancer [74] and the OSHA report [20], both of which had been widely circulated throughout US and UK trade union networks [75]. While Epstein generally warned about occupational and environmental carcinogens, the OSHA report estimated that 20 to $38 \%$ of cancer deaths were occupationally related, leading to numerous debates as to why cancers were on the rise and what policies were needed. In their report, Doll and Peto state that their "principal aim has been to explain matters to interested non-specialists" [9]. Therefore, it is difficult to classify their report as a scientific work, an expert report, or an exercise in popularization [76]. Despite this ambiguous status, the authors' scientific reputation helped lend this report great scientific and social legitimacy while contributing "to temper a growing anxiety at the time about a possible cancer epidemic resulting from occupational exposures" [10]. It also sustained the anti-regulatory policies that developed after President Reagan's election, as noted by the OTA administrator who hired the two scientists [75].

This brief foray into the recent past merely serves as a reminder that, despite common practice, scientific work should also be placed in a social and historical context and not considered to be a purely intellectual construct. When analyzing controversies in science studies, such as those that have developed around PAFs of occupational cancer, it is important to pay equal attention to the winners and losers in order to understand the precise rationale of both sides [77]. It is useful to look at the approaches that have been discarded and the moments when certain scientific choices have been made, as such an exercise may help explain the greater difficulty that epidemiology faces in trying to grasp some of the issues that have persisted until today. Our idea here is to make 
epidemiology less dependent on the previous ways that it faced some issues. Although we cannot propose definite solutions, we endeavor to share some avenues to be explored in future research, some of which have already proved either useful or promising. In our mind, there can be great value in rethinking at least three main areas for change: focus, scope, and metrics.

\section{Change Focus? Towards a Perspective on Population Health Inequities}

The Euro-GBD-SE consortium estimated that the share of deaths from cancer that might be avoided among men aged 30-59 if all occupational groups experienced the mortality of the upper non-manual workers varied between 7 and $46 \%$, depending on country [53*0]. As mentioned earlier, we so far have not found any such estimates relating specifically to occupational exposures and cancer. Based on a secondary analysis of a case-control study, one unique example made use of recent advances in mediation analysis to quantify the extent to which occupational exposures and smoking mediated the association between education and lung cancer incidence in men [78•]. Although we assume that the dearth of proper datae.g., complete, multi-factorial, and stratified on relevant socioeconomic and occupational indicators - makes it a real challenge, we strongly encourage research and surveillance initiatives that could fill this gap by switching from a perspective on population health to one on population health inequities when trying to assess the burden of work-related cancer. In that respect, the choice of occupational classification scheme seems to be all the more important, as an increasing amount of empirical evidence indicates that the worksome - an extension of the exposome - encompasses far more than physical and chemical hazards [79••].

\section{Change Scope? From Occupational Exposures to Work and Employment}

A related issue concerns whether we should broaden our definition of "occupational cancer" to informal or less recognized work situations, for instance, those that affect female sex workers (exposure to HPV infection [80]), open-air workers (exposure to UV light [81]), and people working in bars and restaurants (alcohol intake, active smoking, and environmental tobacco smoke [12]). However, beyond those potentially new combinations of exposures and tumors that may each be important for the specific at-risk occupational groups, changing scope could also make it necessary to broaden the conceptual model by which we link work and health, cancer risk being no a priori exception. A thorough review of the literature did gather the best evidence of the different pathways through which work shapes the social gradient in health [37]. Apart from taking into account the most established hazardous exposures (physical and chemical) as well as job status (which overlaps particularly with one's socioeconomic position), it is also necessary to consider work stress, work organization, and precarious employment, with the latter receiving increasingly more attention over the last decade [82•]. The underlying conceptual model makes it clear that - beyond specific occupational exposures that are strictly definedlower-status workers tend to accumulate various disadvantages across their working life. The model also questions the extent to which employment and working conditions broadly influence health behaviors through job strain and other adverse aspects, although we found very few studies that considered physical/chemical hazards together with psychosocial job stressors in relation to smoking, alcohol consumption, dietary habits, and physical activity [83-85]. Relevant information on the hidden components of the occupational gradient could be gained by documenting employment trajectories, hazardous working conditions, health behaviors, and outcomes among underserved populations, possibly through the follow-up of lower-income cohorts.

\section{Change Metrics? From Relative to Absolute Measures}

Although this review does not intend to provide insight into the many and well-studied validity issues that are particular to attribution and $\mathrm{AF}$ estimation (for a recent overview, see $[4 \bullet \cdot]$ and, for a general presentation, see $[5$, $86])$, we feel it is important to at least mention the more fundamental misconceptions and problems of interpretation that have been raised in the literature. Indeed, they occur equally among studies on work-related cancer and may well provide an opportunity for changing metrics or at least for combining different metrics, as each one may highlight a particular aspect that a single indicator would not fully capture. Two recent reviews have summarized the main pitfalls related to the conceptualization, interpretation, and application of AFs, and they most notably address terminological confusion, the invalid summing of PAFs and calculating the complement of PAFs to $100 \%$ [3], and underestimating the fraction of events in which exposure played a causal role (the etiologic fraction) $\left[87 \cdot, 88^{\bullet}\right]$. Alternative measures of public health impact have been proposed in order to overcome some of those limitations, such as average age at onset [89] or years of potential life lost [90], as well as broader calls to move from relative to absolute metrics [91]. Although such approaches are used far less and still debated [92], we do think more space should be given to scrutinizing the unintentional adverse effects of some of our long-held scientific habitus, including the claim that rate ratios are better than rate differences at capturing both strength of association and public health impact. 


\section{Conclusions}

Going back to the question of the way in which PAFs shape the agendas of both research and public health policies, we should note that when even estimates of modest size $(4-5 \%)$ are considered in isolation, they are often still accompanied by strong statements on "the value of prevention focused on the (relatively small) subpopulations that assume such risks" [93]. Other authors note that "care must be taken not to permit a disregard for a risk with a small PAF (e.g., occupation)" [94]. There are still many uncertainties surrounding the true magnitude of the occupational cancer burden $[11 \bullet \cdot$ ], specifically in regard to the continuing use of known agents and the introduction of potentially new carcinogens; a decrease in exposures to some well-characterized agents in HIC; a decrease in the industrial workforce; the transfer of remaining exposures to more precarious workers in HIC; and the fact that most hazardous industries are moving to lower and middle income countries. In contrast and in spite of those warnings, when using PAFs to compare "preventable causes of cancer," those related to occupational exposures almost invariably rank low. This relative downgrading may well contribute to shaping perceptions that occupational cancers are no longer a public health priority, if they ever were over the last 40 years. It is even more concerning that occupational factors were not included in the latest estimates of the fraction of cancer attributable to modifiable risk factors in the USA, Canada, and Australia, which is due to "lack of credible or useable prevalence data" [95] in some cases or they were excluded in others without explanation [96, 97]. Those different estimates thus focus essentially on modifiable behaviors. This same choice was made by the American Association for Cancer Research in its latest progress report, which, for the first time, did not include estimates of PAFs for occupational exposures [98].

As the demand grows for easy-to-use quantitative indicators for informing public decisions, the time has arrived for rethinking how we calculate PAFs by adopting a perspective on health equity [99・•]. This is of particular relevance in the light of the effects of PAFs on health policies and on the public debates regarding how work contributes to inequities in cancer-although the effects are bound to extend far beyond this single health outcome. As environmental health issues increasingly become a priority, it may also be useful to remember that concerns about these issues originated historically with scientists such as hygienists, toxicologists, and physicians who were studying occupational hazards ranging from those in factories to environmental issues [100]. Perhaps now is also the time to ensure that environmental concerns do not lead to a neglect of occupational health issues.
Acknowledgments EHESP (Modalité Sept, 2018) and Fondation de France for funding this research. Thanks to Dominique Diguet (Ined) and Myriam Fayad (Ehesp) for their precious help in reviewing the literature, to Steve Stellman and Mary Beth Terry at the MSPH (Columbia University) for their thoughtful conversations that nourished the writing of the present paper, and to Christophe Paris (Inserm-Rennes 1 University) for his careful reading.

\section{Compliance with Ethical Standards}

Conflict of Interest The authors declare that they have no conflict of interest.

Human and Animal Rights and Informed Consent This article does not contain any studies with human or animal subjects performed by any of the authors.

Open Access This article is distributed under the terms of the Creative Commons Attribution 4.0 International License (http:// creativecommons.org/licenses/by/4.0/), which permits unrestricted use, distribution, and reproduction in any medium, provided you give appropriate credit to the original author(s) and the source, provide a link to the Creative Commons license, and indicate if changes were made.

\section{References}

Papers of particular interest, published recently, have been highlighted as:

- Of importance

•. Of major importance

1. Doll R. On the aetiology of cancer of the lung. Acta - Unio Int Contra Cancrum. 1951;7(1 Spec):39-50.

2. Levin ML. The occurrence of lung cancer in man. Acta - Unio Int Contra Cancrum. 1953;9(3):531-41.

3.・ Poole C. A history of the population attributable fraction and related measures. Ann Epidemiol. 2015;25(3):147-54 A concise and comprehensive review of methods spanning from 1951 to the late 1980s.

4.• Shield KD, Parkin DM, Whiteman DC, Rehm J, Viallon V, Micallef CM, et al. Population attributable and preventable fractions: cancer risk factor surveillance, and cancer policy projection. Curr Epidemiol Rep. 2016;3(3):201-11 An overview of common methods combining $R R$ and prevalence data and of the main assumptions to be met.

5. Rockhill B, Newman B, Weinberg C. Use and misuse of population attributable fractions. Am J Public Health. 1998 Jan;88(1): $15-9$.

6.• Cairney P. The politics of evidence-based policy making. London: Palgrave Macmillan UK; 2016. 152 p. A social and political sciences contribution to the current debate on the relationship between science and public policy.

7. Bray F, Soerjomataram I. Population attributable fractions continue to unmask the power of prevention. Br J Cancer. 2018 Apr;118(8):1031-2.

8. Rushton L. The global burden of occupational disease. Curr Environ Health Rep. 2017;4(3):340-8.

9. Doll R, Peto R. The causes of cancer: quantitative estimates of avoidable risks of cancer in the United States today. J Natl Cancer Inst. 1981 Jun;66(6):1191-308. 
10. Blot WJ, Tarone RE. Doll and Peto's quantitative estimates of cancer risks: holding generally true for 35 years. JNCI J Natl Cancer Inst. 2015 Apr 1 [cited 2018 Oct 23];107(4). Available from: https://academic.oup.com/jnci/article/107/4/djv044/ 894954.

11.• Purdue MP, Hutchings SJ, Rushton L, Silverman DT. The proportion of cancer attributable to occupational exposures. Ann Epidemiol. 2015;25(3):188-92 The latest review of published estimates of attributable fractions for work-related cancer.

12. Rushton L, Hutchings SJ, Fortunato L, Young C, Evans GS, Brown T, et al. Occupational cancer burden in Great Britain. Br J Cancer. 2012;107:S3-7.

13. Steenland K, Burnett C, Lalich N, Ward E, Hurrell J. Dying for work: the magnitude of US mortality from selected causes of death associated with occupation. Am J Ind Med. 2003 May 1;43(5): 461-82.

14.• Marant Micallef C, Shield KD, Vignat J, Baldi I, Charbotel B, Fervers B, et al. Cancers in France in 2015 attributable to occupational exposures. Int J Hyg Environ Health. 2019;222(1):22-9 The latest estimates of work-related cancer in France based on an extensive collection of national data.

15. Brown KF, Rumgay H, Dunlop C, Ryan M, Quartly F, Cox A, et al. The fraction of cancer attributable to modifiable risk factors in England, Wales, Scotland, Northern Ireland, and the United Kingdom in 2015. Br J Cancer. 2018;118(8):1130-41.

16. Melaku YA, Appleton SL, Gill TK, Ogbo FA, Buckley E, Shi Z, et al. Incidence, prevalence, mortality, disability-adjusted life years and risk factors of cancer in Australia and comparison with OECD countries, 1990-2015: findings from the Global Burden of Disease Study 2015. Cancer Epidemiol. 2018;52:43-54.

17. Schottenfeld D, Beebe-Dimmer JL, Buffler PA, Omenn GS. Current perspective on the global and United States cancer burden attributable to lifestyle and environmental risk factors. Annu Rev Public Health. 2013;34(1):97-117.

18. Labrèche F, Duguay P, Boucher A, Arcand R. But other than mesothelioma? An estimate of the proportion of work-related cancers in Quebec. Curr Oncol. 2016;23(2):e144-9 The latest estimates of work-related cancer in Québec adapted from published attributable fractions.

19. Parkin DM. 14. Cancers attributable to occupational exposures in the UK in 2010. Br J Cancer. 2011;105(S2):S70-2.

20. Bridbord K, Decoufle P, Fraumeni J, Hoel D, Hoover R, Rall D, et al. Estimates of the fraction of cancer in the United States related to occupational factors. Prepared by National Cancer Institute, National Institute of Environmental Health Sciences and National Institute for Occupational Safety and Health, Bethesda, USA. 1978;52.

21. Dreyer L, Andersen A, Pukkala E. Avoidable cancers in the Nordic countries. Occupation APMIS Suppl. 1997;76:68-79.

22. Nurminen M, Karjalainen A. Epidemiologic estimate of the proportion of fatalities related to occupational factors in Finland. Scand J Work Environ Health. 2001;27(3):161-213.

23. Zahm SH, Blair A. Occupational cancer among women: where have we been and where are we going? Am J Ind Med. 2003;44(6):565-75.

24. Hohenadel K, Raj P, Demers PA, Zahm SH, Blair A. The inclusion of women in studies of occupational cancer: a review of the epidemiologic literature from 1991-2009. Am J Ind Med. 2015;58(3):276-81.

25. Betansedi C-O, Vaca Vasquez P, Counil E. A comprehensive approach of the gender bias in occupational cancer epidemiology: a systematic review of lung cancer studies (2003-2014). Am J Ind Med. 2018;61(5):372-82.

26. Hutchings SJ, Rushton L. Occupational cancer in Britain. Industry sector results. Br J Cancer. 2012;107(S1):S92-103.
27. Gilg Soit Ilg A, Houot M, Pilorget C. Estimation de parts de cancers attribuables à certaines expositions professionnelles en France. Utilisation des matrices emplois-expositions développées dans le cadre du programme Matgéné. [Internet]. Saint-Maurice: Santé publique France; 2016 p. 40. Available from: http://www. santepubliquefrance.fr. Accessed 19 April 2019.

28. De Matteis S, Consonni D, Bertazzi PA. Exposure to occupational carcinogens and lung cancer risk. Evolution of epidemiological estimates of attributable fraction. Acta Bio-Medica Atenei Parm. 2008;79 Suppl 1:34-42.

29. Wild P, Gonzalez M, Bourgkard E, Courouble N, ClémentDuchêne C, Martinet Y, et al. Occupational risk factors have to be considered in the definition of high-risk lung cancer populations. Br J Cancer. 2012;106(7):1346-52.

30. Boffetta P, Kogevinas M, Simonato L, Wilbourn J, Saracci R. Current perspectives on occupational cancer risks. Int J Occup Environ Health. 1995;1(4):315-25.

31. Proctor R, Schiebinger LL, editors. Agnotology: the making and unmaking of ignorance. Stanford: Stanford University Press; 2008. $298 \mathrm{p}$

32.• Hess DJ. Undone science: social movements, mobilized publics, and industrial transitions. Cambridge: MIT Press; 2016. 250 p. A presentation of the concept of "undone science" that builds on the bridging of social movement studies and science and technology studies.

33. Schrijvers CT, van de Mheen HD, Stronks K, Mackenbach JP. Socioeconomic inequalities in health in the working population: the contribution of working conditions. Int J Epidemiol. 1998 Dec;27(6):1011-8.

34. Lipscomb HJ, Loomis D, McDonald MA, Argue RA, Wing S. A conceptual model of work and health disparities in the United States. Int J Health Serv Plan Adm Eval. 2006;36(1):25-50.

35. Murray LR. Sick and tired of being sick and tired: scientific evidence, methods, and research implications for racial and ethnic disparities in occupational health. Am J Public Health. 2003;93(2):221-6.

36. Krieger N. Workers are people too: societal aspects of occupational health disparities - an ecosocial perspective. Am J Ind Med. 2010;53(2):104-15.

37. Clougherty JE, Souza K, Cullen MR. Work and its role in shaping the social gradient in health. Ann N Y Acad Sci. 2010;1186(1): 102-24.

38.• Ahonen EQ, Fujishiro K, Cunningham T, Flynn M. Work as an inclusive part of population health inequities research and prevention. Am J Public Health. 2018;108(3):306-11 An analytic assay arguing for the inclusion of work in public health research and practice to advance health equity.

39. Hall AL, Peters CE, Demers PA, Davies HW. Exposed! Or not? The diminishing record of workplace exposure in Canada. Can J Public Health Rev Can Sante Publique. 2014;105(3):e214-7.

40. Scarselli A, Montaruli C, Marinaccio A. The Italian information system on occupational exposure to carcinogens (SIREP): structure, contents and future perspectives. Ann Occup Hyg. 2007;51(5):471-8.

41. Kauppinen T, Toikkanen J, Pedersen D, Young R, Ahrens W, Boffetta P, et al. Occupational exposure to carcinogens in the European Union. Occup Environ Med. 2000;57(1):10-8.

42. Peters CE, Ge CB, Hall AL, Davies HW, Demers PA. CAREX Canada: an enhanced model for assessing occupational carcinogen exposure. Occup Environ Med. 2015;72(1):64-71.

43. Carey RN, Driscoll TR, Peters S, Glass DC, Reid A, Benke G, et al. Estimated prevalence of exposure to occupational carcinogens in Australia (2011-2012). Occup Env Med. 2014;71(1):5562.

44. Havet N, Penot A, Morelle M, Perrier L, Charbotel B, Fervers B. Varied exposure to carcinogenic, mutagenic, and reprotoxic 
(CMR) chemicals in occupational settings in France. Int Arch Occup Environ Health. 2017;90(2):227-41 One of the few published estimates of exposures to CMRs stratified on occupation based on a national survey conducted periodically.

45. Havet N, Penot A, Morelle M, Perrier L, Charbotel B, Fervers B. Trends in occupational disparities for exposure to carcinogenic, mutagenic and reprotoxic chemicals in France 2003-10. Eur J Public Health. 2017;27(3):425-32.

46. Havet N, Penot A, Plantier M, Charbotel B, Morelle M, Fervers B. Inequalities in the control of the occupational exposure in France to carcinogenic, mutagenic and reprotoxic chemicals. Eur J Public Health [Internet]. 2018 [cited 2018 Nov 13]; Available from: https://academic-oup-com.gate2.inist.fr/eurpub/advance-article/ doi/10.1093/eurpub/cky130/5060424.

47. Okechukwu CA, Souza K, Davis KD, de Castro AB. Discrimination, harassment, abuse and bullying in the workplace: contribution of workplace injustice to occupational health disparities. Am J Ind Med. 2014;57(5):573-86.

48. Landsbergis PA, Grzywacz JG, LaMontagne AD. Work organization, job insecurity, and occupational health disparities. Am J Ind Med. 2014;57(5):495-515.

49. Krieger N, Chen JT, Waterman PD, Hartman C, Stoddard AM, Quinn MM, et al. The inverse hazard law: blood pressure, sexual harassment, racial discrimination, workplace abuse and occupational exposures in US low-income black, white and Latino workers. Soc Sci Med 1982. 2008;67(12):1970-81.

50. Rey G, Rican S, Luce D, Menvielle G, Jougla E. Measuring social inequalities in cause-specific mortality in France: comparison between linked and unlinked approaches. Rev Epidemiol Sante Publique. 2013 Jun;61(3):221-31.

51. Vanthomme K, Van den Borre L, Vandenheede H, Hagedoorn P, Gadeyne S. Site-specific cancer mortality inequalities by employment and occupational groups: a cohort study among Belgian adults, 2001-2011. BMJ Open [Internet]. 2017 Nov 12 [cited 2018 Nov 21];7(11). Available from: https:/www.ncbi.nlm.nih. gov/pmc/articles/PMC5695485/.

52. Bertuccio P, Alicandro G, Sebastiani G, Zengarini N, Costa G, La Vecchia $\mathrm{C}$, et al. Mortality by occupation-based social class in Italy from 2012 to 2014. Int J Public Health. 2018;63(7):865-74.

53.•• Toch-Marquardt M, Menvielle G, Eikemo TA, Kulhánová I, Kulik MC, Bopp M, et al. Occupational class inequalities in all-cause and cause-specific mortality among middle-aged men in 14 European populations during the early 2000s. PLoS ONE [Internet]. 2014 Sep 30 [cited 2018 Nov 21];9(9). Available from: https://www.ncbi.nlm.nih.gov/pmc/articles/PMC4182439/. The only work we found that used PAFs to quantify the potential reduction in cause-specific mortality based on the comparison of occupational groups.

54. Pukkala E, Martinsen JI, Lynge E, Gunnarsdottir HK, Sparén P, Tryggvadottir L, et al. Occupation and cancer-follow-up of 15 million people in five Nordic countries. Acta Oncol Stockh Swed. 2009:48(5):646-790.

55. Mackenbach JP, Kulhánová I, Menvielle G, Bopp M, Borrell C, Costa $\mathrm{G}$, et al. Trends in inequalities in premature mortality: a study of 3.2 million deaths in 13 European countries. J Epidemiol Community Health. 2015 Mar 1;69(3):207-17.

56. Hoffmann R, Kröger H, Pakpahan E. Pathways between socioeconomic status and health: does health selection or social causation dominate in Europe? Adv Life Course Res. 2018;36:23-36.

57. Fox AJ, Adelstein AM. Occupational mortality: work or way of life? J Epidemiol Community Health. 1978;32(2):73-8.

58. Kogevinas M, Pearce N, Susser M, Boffetta P. Social inequalities and cancer [Internet]. Lyon: IARC; 1997 [cited 2018 Nov 24]. 405 p. (IARC Scientific Publication). Available from: http:// publications.iarc.fr/Book-And-Report-Series/Iarc-ScientificPublications/Social-Inequalities-And-Cancer-1997.
59. Kjaerheim K, Martinsen JI, Lynge E, Gunnarsdottir HK, Sparen P, Tryggvadottir L, et al. Effects of occupation on risks of avoidable cancers in the Nordic countries. Eur J Cancer Oxf Engl 1990. 2010;46(14):2545-54

60. Parascandola M. Skepticism, statistical methods, and the cigarette: a historical analysis of a methodological debate. Perspect Biol Med. 2004;47(2):244-61.

61. Hueper WC. Occupational tumors and allied diseases. Springfield: C. C. Thomas; 1942. p. xxviii. 896 p., 1 1. incl. tables

62. Sellers CC. Discovering environmental cancer: Wilhelm Hueper, post-World War II epidemiology, and the vanishing clinician's eye. Am J Public Health. 1997;87(11):1824-35.

63. Rothman KJ, Greenland S, Lash TL. Modern epidemiology. Third ed. Wolters Kluwer Health, Lippincott Williams \& Wilkins: Philadelphia; 2008. 758 p.

64. Jorland G, Opinel A, Weisz G, editors. Body counts: medical quantification in historical and sociological perspective = La quantification medicale, perspectives historiques et sociologiques. Montréal: McGill-Queen's University Press; 2005. 417 p

65. Straif K. Estimating the burden of occupational cancer as a strategic step to prevention. Br J Cancer. 2012;107:S1-2.

66. Rushton L. Occupational cancer: recent developments in research and legislation. Occup Med. 2017;67(4):248-50.

67. Clapp RW, Howe GK, Jacobs M. Environmental and occupational causes of cancer re-visited. J Public Health Policy. 2006;27(1):6176.

68. Christiani DC. Combating environmental causes of cancer. N Engl J Med. 2011;364(9):791-3.

69. Willett WC, Colditz GA, Hiatt RA. Combating environmental causes of cancer. N Engl J Med. 2011;364(23):2266-8.

70. Tarone RE, McLaughlin JK. Combating environmental causes of cancer. N Engl J Med. 2011;364(23):2266-7 author reply 22672268.

71. Morgenstern H, Bursic ES. A method for using epidemiologic data to estimate the potential impact of an intervention on the health status of a target population. J Community Health. 1982;7(4):292-309.

72. Cherrie JW, Hutchings S, Gorman Ng M, Mistry R, Corden C, Lamb J, et al. Prioritising action on occupational carcinogens in Europe: a socioeconomic and health impact assessment. Br J Cancer. 2017;117(2):274-81.

73. Henry E. Ignorance scientifique et inaction publique: les politiques de santé au travail. Paris: SciencesPo les presses; 2017. 256 p. (Domaine Gouvernances)

74. Epstein SS. The politics of cancer. San Francisco: Sierra Club Books; 1978. $583 \mathrm{p}$

75. Proctor RN. Cancer wars: how politics shapes what we know and don't know about Cancer. New York: Basic Books; 1996. 368 p

76. Hilgartner S. The dominant view of popularization: conceptual problems, political uses. Soc Stud Sci. 1990;20(3):519-39.

77. Bloor D. Knowledge and social imagery. London: Routledge \& K. Paul; 1976. 156 p. (Routledge direct editions)

78. Menvielle G, Franck J-E, Radoï L, Sanchez M, Févotte J, Guizard $\mathrm{A}-\mathrm{V}$, et al. Quantifying the mediating effects of smoking and occupational exposures in the relation between education and lung cancer: the ICARE study. Eur J Epidemiol. 2016;31(12):1213-21 The only work we found that tried to decompose educational inequalities in lung cancer incidence due to smoking and occupational exposures.

79.•• Eyles E, Manley D, Jones K. Occupied with classification: which occupational classification scheme better predicts health outcomes? Soc Sci Med [Internet]. 2018 Sep 15 [cited 2018 Nov 14]; Available from: http://www.sciencedirect.com/science/ article/pii/S0277953618305100. An important contribution to the discussion on socioeconomic indicators in epidemiologic research introducing the concept of worksome. 
80. Soohoo M, Blas M, Byraiah G, Carcamo C, Brown B. Cervical HPV infection in female sex workers: a global perspective. Open AIDS J. 2013;7:58-66.

81. Rushton L, Hutchings SJ. The burden of occupationally-related cutaneous malignant melanoma in Britain due to solar radiation. Br J Cancer. 2017;116(4):536-9.

82. Benach J, Vives A, Amable M, Vanroelen C, Tarafa G, Muntaner C. Precarious employment: understanding an emerging social determinant of health. Annu Rev Public Health. 2014;35:229-53 A thorough review of the multidimensional definitions of precarity of employment and of the mechanisms through which it may impact health inequalities.

83. Okechukwu CA, Krieger N, Chen J, Sorensen G, Li Y, Barbeau EM. The association of workplace hazards and smoking in a U.S. multiethnic working-class population. Public Health Rep. 2010;125(2):225-33.

84. Chin DL, Hong O, Gillen M, Bates MN, Okechukwu CA. Cigarette smoking in building trades workers: the impact of work environment. Am J Ind Med. 2012;55(5):429-39.

85. Sorensen G, Stoddard A, Hammond SK, Hebert JR, Avrunin JS, Ockene JK. Double jeopardy: workplace hazards and behavioral risks for craftspersons and laborers. Am J Health Promot AJHP. 1996;10(5):355-63.

86. Steenland K, Armstrong B. An overview of methods for calculating the burden of disease due to specific risk factors. Epidemiol Camb Mass. 2006;17(5):512-9.

87. Greenland S. Concepts and pitfalls in measuring and interpreting attributable fractions, prevented fractions, and causation probabilities. Ann Epidemiol. 2015;25(3):155-61 A summary of previous papers raising conceptual and methodological issues related to PAFs that are often overlooked.

88. Greenland S, Robins JM. Conceptual problems in the definition and interpretation of attributable fractions. Am J Epidemiol. 1988;128(6):1185-97.

89. Boshuizen HC, Greenland S. Average age at first occurrence as an alternative occurrence parameter in epidemiology. Int J Epidemiol. 1997;26(4):867-72.

90. Bang KM, Mazurek JM, Wood JM, Hendricks SA. Diseases attributable to asbestos exposure: years of potential life lost, United States, 1999-2010. Am J Ind Med. 2014;57(1):38-48.
91. Poole C. On the origin of risk relativism. Epidemiology. 2010;21(1):3-9.

92. Morfeld P. Years of life lost due to exposure: causal concepts and empirical shortcomings. Epidemiol Perspect Innov. 2004;1:5.

93. Cullen MR. Invited commentary: the search for preventable causes of cardiovascular disease-whither work? Am J Epidemiol. 2009;169(12):1422-5.

94. Rothenberg R. The causes of cancer, revisited. Ann Epidemiol. 2015;25(3):215-6.

95. Whiteman DC, Webb PM, Green AC, Neale RE, Fritschi L, Bain CJ, et al. Cancers in Australia in 2010 attributable to modifiable factors: introduction and overview. Aust N Z J Public Health. 2015;39(5):403-7.

96. Islami F, Goding Sauer A, Miller KD, Siegel RL, Fedewa SA, Jacobs EJ, et al. Proportion and number of cancer cases and deaths attributable to potentially modifiable risk factors in the United States. CA Cancer J Clin. 2018;68(1):31-54.

97. Brenner DR, Poirier AE, Walter SD, King WD, Franco EL, Demers PA, et al. Estimating the current and future cancer burden in Canada: methodological framework of the Canadian population attributable risk of cancer (ComPARe) study. BMJ Open. 2018;8(7):e022378.

98. AACR. AACR cancer progress report 2018 [Internet]. Philadelphia: American Association for Cancer Research; 2018 [cited 2018 Nov 15] p. 149. (cancerprogressreport.org). Available from: https://www.cancerprogressreport.org.

99.• Krieger N. Health equity and the fallacy of treating causes of population health as if they sum to $100 \%$. Am J Public Health. 2017;107(4):541-9 A clear demonstration of common misuse and misreporting of PAFs and how they can play against improving research and intervention on population health equity.

100. Sellers CC. Hazards of the job: from industrial disease to environmental health science. Chapel Hill: University of North Carolina Press; $1997.331 \mathrm{p}$

Publisher's Note Springer Nature remains neutral with regard to jurisdictional claims in published maps and institutional affiliations. 